\title{
THE ROLE OF THE SOCIAL WORKER IN THE PREVENTION OF CHILD TRAFFICKING IN SOUTH AFRICA
}

\section{Juliet Patience Sambo, Gloudien Spies}

\section{INTRODUCTION}

According to the United Nations Palermo Protocol (2000:14), child trafficking is defined as the recruitment, transportation, transfer, harbouring or receipt of children through threats, force, coercion, abduction, fraud and/or deception. Child trafficking takes many different forms. Some children are forcibly abducted, others are tricked and still others opt to be trafficked, seduced by the promise of earnings, but unaware of the level of exploitation they will go through at the end of the recruiting chain. Child trafficking always involves a journey, whether within the country or across the border. At the final destination trafficked children become part of the underworld of criminality and illegality into which they are plunged (United Nations Children Fund, 2005:49).

Close to home, internal trafficking of children occurs in South Africa largely for reasons to do with labour and sexual exploitation. However, South Africa is also the major destination for regional and extra-regional trafficking activities (Martens, Pieczkowski \& Vuuren-Smith, 2003:125). It is reportedly Africa's major cross-border destination for receiving children trafficked from over ten countries. Female children are the primary victims, although male children have also been identified as victims (International Organisation for Migration, 2003:13).

The purpose of the study was to explore the experiences of social workers regarding their role in the prevention of child trafficking in South Africa. In-depth one-to-one interviews were conducted with the whole population of the respondents found in the selected organisations. Data were gathered according to the following themes, which formed part of the interview schedule:

- Theoretical understanding of the concept of child trafficking;

- Views on the role of the social worker in the prevention of child trafficking;

- Perceptions regarding the services in place to protect victims of child trafficking;

- Experiences regarding obstacles social workers face in the prevention of child trafficking;

- Views on the availability of resources to support social workers in the prevention of child trafficking;

- Knowledge about the existing legislation related to child trafficking in South Africa; and

- Perceptions on training needs of social workers in the field of child trafficking.

\section{BACKGROUND TO THE RESEARCH}

South Africa, as part of the global village, is not immune to internal and cross-border child trafficking phenomena. According to SANGONet (2004:2,4), a child rights organisation reported that the Western Cape (especially Cape Town), Gauteng (especially Johannesburg), the Eastern Cape and KwaZulu-Natal are the major recruiting centres in South Africa for child trafficking for sexual exploitation, domestic work and farm labour purposes. It is against this background that the researcher was motivated to explore the role of the social worker in the prevention of this phenomenon. 


\section{The factors that contribute to child trafficking}

According to Kelly, Maghan and Serio (2005:142) and Redlinger (2004:22-23), there are a number of factors contributing to child trafficking, including poverty, gender discrimination, natural disasters and political instability, culture, HIV/AIDS, weak laws and corrupt law enforcement, globalisation, new communication and technology, family dysfunction and breakdown, social developmental strategies, rituals in which human private parts are used, and lack of birth registration. These factors lead children along a trail of traumatic experiences with negative physical, social, psychological and economic impacts.

\section{The impact of child trafficking}

Child trafficking has a negative impact on victims and their families as well as the community and the nation as a whole. Child trafficking is a human rights violation and a crime. It violates the universal rights of all children to life, liberty and freedom from slavery. Where child trafficking occurs, it increases social breakdown and promotes crime, and interrupts the passage of knowledge and cultural values from parent to child and from generation to generation, making the child more vulnerable to the traffickers and weakening a core pillar of society (Redlinger 2004:24). In short, child trafficking leads to social, psychological, physical and economic trauma for the victim (McDonnell, 2006:8).

\section{Perpetrators of child trafficking}

Dottridge (2004:24-33) states that children are recruited by their parents or relatives and close friends, government agencies and commercial agencies. These groups recruit the children both for the entertainment industry and as domestic workers. Other recruiters might be community leaders and prominent members in the society such as village headmen, church leaders, police officers, orphanage directors, brothel owners, local doctors, bank officials, all sorts of transport workers, tour operators and criminal gangs. Furthermore, professionals including adoption officers, school teachers and government officials in justice (e.g. lawyers) and health departments are also involved in recruiting children. Corrupt immigration officials may facilitate the act consciously or unconsciously, but the bottom line is that child trafficking is a business in which a lot of people have a stake.

\section{Indicators which show that the child is a victim of trafficking}

Mertinez (2007:9) and Kelly et al. (2005:143) provide a number of indicators which are used to identify children who have been trafficked. These include features such as the children being typically malnourished and dehydrated as a result of poor hygiene and starvation as well as lack of proper care, and as a consequence the children's health deteriorates. Also, the children get caught up in debt bondage and this means that the victims cannot send money home because they are forced to pay back debts. The children show signs of rape and sexual abuse, coupled with sexually transmitted infections (Dottridge, 2004:26), as well as experiencing posttraumatic stress disorder (PTSD). The victims are kept in isolation in heavy-security buildings with barred windows, locked doors and in isolated locations with electronic surveillance. Their travel and all identification documents are confiscated and usually they cannot speak the local language. Furthermore, the victims are afraid of the perpetrators, because they resort to violence and threats, forcing the victim to comply with their demands. The perpetrators abuse the victims physically and threaten to kill them if they do not comply with the orders dictated to them. The victims will also tolerate abuse in order to protect their families, that is, if a family member was involved in facilitating the trafficking transaction (Clawson, Salomon \& Grace, 2008:2-3). 
Challenges in meeting the needs of trafficked children who experience traumatic abuse

Several reasons explain the challenges in meeting the needs of trafficked children in South Africa. Clawson et al. (2008:3) state that limited availability of, and access to, appropriate mental health services are a significant challenge for both international and domestic child victims of trafficking. Additionally, it is difficult to establish relationships of trust with victims. According to Clawson et al. (2008:4), the mistrust that characterises victims is often a result of their history of betrayal by families, service systems and, in some cases, law enforcement officials and governments. Moreover, the victims' mistrust is often compounded by fears that any connection with law enforcement or service providers can compromise their safety. Furthermore, Clawson et al. (2008:4) argue that mandated treatment efforts may be counterproductive when working with victims of child trafficking. Having already experienced loss of control to traffickers, victims can find detention centres particularly threatening and essentially re-traumatising, which might compromise the process of their recovery. Ugartel, Zarate and Farley (2003:147-165) have indicated that secrecy is a trademark of boys and girls involved in sex trafficking. Victims may not define their experience as abusive, or attempt to escape. If victims do not define their experiences as abusive, no matter how serious such experiences may be, they are unlikely to seek help or engage in recovery programmes. According to Hotaling, Burris, Johnson, Bird and Melbye (2003:257), foreign-born trafficked victims face additional barriers related to language, culture and isolation. The lack of English and local language skills limits their ability to access information about their rights, services and options. Isolation as a result of these language barriers as well as cultural differences can be hard and devastating for trafficked victims, resulting in reinforcement of their captivity. This is true even of local victims moved throughout the country.

\section{THE ROLE OF THE SOCIAL WORKER IN THE PREVENTION OF CHILD TRAFFICKING}

The International Labour Organisation (2006a:15) states that child victims of trafficking endure harmful repercussions that affect their physical and mental health, contributing to personality and behavioural disorders which disturb normal child development. These negative impacts require a range of prevention measures, represented by the various professions in a multidisciplinary team including social workers. The role of the social worker in the prevention of child trafficking will be discussed below and will include primary, secondary and tertiary prevention.

\section{PRIMARY PREVENTION}

The target groups of primary prevention are all the children in society. Primary prevention involves a situation whereby the social workers become proactive in their approach in their efforts to curb child trafficking. This approach encourages them to organise and conduct child trafficking awareness campaigns and support the campaigns with information, training and media production (Thaichildrights, 2008:2). These may focus on a number of approaches.

\section{Run information and awareness campaigns}

Community-based child-run radio and television programmes: This is a good practice at provincial level in one of the high-risk sending zones - for example, areas near the Messina and Mozambique borders as well as places that attract tourists, the central business districts of Pretoria, Johannesburg, Durban and Cape Town, and rural areas. Such information and awareness campaigns are radio and television activities led by trained children with the assistance of a child welfare organisation. The radio and television station should be attached to 
drop-in centres that offer education and recreational activities to community children. The radio and television programmes help to prevent child trafficking by promoting the participation of children in the fight against trafficking (International Labour Organisation, 2006b:26).

Drama groups: Drama groups could focus on raising awareness for behavioural change. The drama performance will present the message of the causes and effects of child trafficking in a form that can be easily understood by children and the community at large. The performance stimulates the audiences to question their assumptions and perceptions about child trafficking and take action (Thijs, 2006:6).

\section{Empowerment projects}

Micro-enterprise development model: The establishment of a micro-enterprise development model for vulnerable families to develop entrepreneurship is important. The social worker has the role to assist vulnerable families to run community-based economies through the formation of enterprises that aim to improve the socio-economic status of families with low levels of literacy in South Africa. This business model helps to prevent child trafficking by improving the economic situation of the families and thus fighting poverty, which is one of the root causes of child trafficking and child labour. It also unlocks the entrepreneurial skills of vulnerable families and empowers family relations (International Labour Organisation, 2006b:2-3).

Empowerment of women: The empowerment of single women, widows and mothers addresses one of the most vulnerable groups in society. The empowerment practice brings this group to the attention of the public so that their problems and needs are appropriately addressed. A counselling programme should be initiated in order to offer traumatised single and widowed women space to cope with their psychosocial difficulties, build their confidence and create a proactive environment for their children (International Labour Organisation, 2006b:49).

Child and youth centres: The importance of establishing child and youth centres cannot be over-emphasised. These are multipurpose centres where vulnerable children and youths can receive training in educational and vocational skills. The educational training programmes must cover what child trafficking entails and how to prevent it (Cincotta, Dispasquale, Holden, Johnson, McIntosh, Paplinger \& Sinclair, 2005:51).

\section{Social mobilisation}

The establishment of community vigilante teams: This involves the voluntary formation of community vigilante teams. The government, NGOs and private organisations must support their activities to raise awareness, detect risk cases and take action against child trafficking. The community vigilante teams help to prevent child trafficking by undertaking surveillance actions in their own communities and collaboratively with nearby communities to detect cases of children at risk, in transit or being trafficked. Furthermore, it is imperative to refer children at risk to relevant organisations, for example, the International Organisation for Migration (IOM) or Childline, to receive appropriate education and welfare services (International Labour Organisation, 2006b:9).

The establishment of vocational skills training: This is a professional vocational package offered to children at high risk of being trafficked, facilitating by child welfare organisations. The model turns crises into opportunities by empowering children with commercial skills that can create opportunities for decent incomes and preserving their dignity (Cincotta et al., 2005:51). 
Mobilise restaurant workers: This seeks to protect children working in restaurants, many of whom are under 18 years and at risk of being trafficked. The initiative includes mobilising the workers as peer leaders against child trafficking, improving the workers' understanding of the dynamics, risks and dangers of child trafficking, and equipping them with leadership and life skills (Global Report on Forced Labour, 2006:45).

\section{Capacity building}

Teacher training: The training of teachers is a crucial step to capacity building and raising awareness for teachers and other education professionals; this is a joint effort of child welfare organisations and the Department of Education. The objective is to improve the quality of education to make formal schooling more attractive to learners. Improved quality education discourages student dropouts and increases the teachers' awareness of child trafficking. The teachers, who are well informed of the dynamics of child trafficking, provide special attention to those children who are more at risk of being trafficked. Engaging and empowering school teachers makes them more effective change agents in the fight against child trafficking (Thijs, 2006:18). Empowered educators are equipped with knowledge of the relevant international instruments and national laws that can protect children.

Training on psychosocial counselling: This is the delivery of a professional training package on psychosocial counselling by a highly specialised institute. The aim is to produce a cadre of competent social workers, counsellors and psychologists who will serve in child welfare organisations caring for victims of trafficking. The training improves the quality of psychosocial counselling and care for victims of child trafficking in South Africa (International Labour Organisation, 2006b:34).

Joint government and NGO efforts: This is a collaboration which aims at enhancing institutional capacity building in the rehabilitation, recovery and reintegration of child victims of trafficking. The purpose of collaboration between the government and NGOs is to utilise a multidisciplinary approach and psychosocial counselling and care. The main feature of the collaboration is the compact training curriculum, which specifically focuses on the needs of returned children. The initiative is built on a good partnership between the government and NGOs (Cincotta et al., 2005:51). This approach entails diverse resources working together for the wellbeing of the trafficked child, the affected family, the community and the country at large.

Anti-trafficking surveillance and cyber-watch unit: This addresses the demand side of child pornography, sexual abuse, paedophilia and trafficking. The model comprises surveillance of pornographic activities on the internet, police foot surveillance of crime sites, the detection of child abuse cases, the arrest and prosecution of perpetrators, and the rescue and rehabilitation of victims. The cyber-watch surveillance unit monitors paedophiles websites, chat rooms and other internet forums in an attempt to entrap paedophiles who come to South Africa to pursue sexual gratification (Cincotta et al., 2005:51; International Labour Organisation, 2006b:58).

Multidisciplinary approach: This is a group of diverse professionals who render services and recommend activities conducted on behalf of each survivor from the time of intake through to the integration stage. The composition of the team usually includes police, medical, legal, psychosocial and social welfare professionals. 


\section{SECONDARY PREVENTION}

Secondary levels of prevention are especially relevant for countries of destination from a medium- and long-term perspective. The target groups of secondary prevention are children who are at risk of being victims of trafficking (Antislavery, 2003:3). Children at risk of being trafficked need to be protected, especially those found in transit to the brothels. Those found at the destinations need to be rescued and protected from being re-trafficked. The following are the services rendered at secondary prevention level.

\section{Treatment/rehabilitation children's homes or shelters}

Children's homes and well secured shelters can be established for comprehensive rehabilitation services for trafficked victims. Secure shelters prevent children from being re-trafficked. The victims of trafficking can benefit from a multidisciplinary and participatory approach, which improves psychosocial care and recovery services.

\section{Rehabilitation centres}

Social workers in rehabilitation centres should work closely with network organisations for referral recovery, reintegration and legal protection services. The social workers should know that it is imperative to draw on existing expertise in offering well-rounded services and building a good network, which involves a multidisciplinary approach. The emphasis on comprehensive services for child victims of trafficking should be in line with the national priorities to strengthen child welfare and protection.

\section{Case management system}

This is an innovative approach for centre-based intervention to offer high-quality services to traumatised children who have been trafficked. The case management system is necessary for the application of a multidisciplinary approach to rehabilitation. The model aims at delivering services to child victims of trafficking by improving institutional capacity building to deal with all aspects of the protection and rehabilitation of survivors. Child participation is also an important aspect to ensure the best interests of the child (International Labour Organisation, 2006b:42). The social worker as the case manager in particular must ensure that the best interests of the child are served. The worker should carry out an individual case assessment to determine needs, develop an individual care and protection plan, and refer the child to appropriate services depending on the needs (ECPAT, 2006:113).

\section{Assistance during legal/court process}

Social workers should prepare and submit to children's courts social work case-study reports with case assessments and recommendations focusing on the best interests of the child. Social workers also have to advise the court role players on child-friendly procedures and ensure that children's best interests are represented during court hearings to avoid re-victimisation (ECPAT, 2006:113).

\section{Involvement in government strategies to develop policies and laws, and monitor implementation}

This point is essential at all levels of prevention strategies. The social worker should be involved in the formulation of anti-trafficking policies and laws which will focus on the prevention of child trafficking and on the criminalisation of the perpetrators. This includes involvement in the drafting of legislation, norms and minimum standards to be followed when rendering services. In addition, there is a need to establish and maintain special law enforcement units for the purpose of investigating cases, rescuing victims and rehabilitation. 
Law enforcement in the prevention of child trafficking in South Africa is effective only if it is implemented. Therefore international and national instruments on child protection must be implemented (Cincotta et al., 2005:51).

\section{TERTIARY PREVENTION}

Antislavery (2003:3) states that tertiary prevention is a long term process which involves rehabilitation and reintegration into the society. The intervention strategies at this level should protect the children from being re-victimised. Thaichildrights (2008:2) adds that the target is to protect the children who have been rescued from the trafficking trap by rendering relevant services. The other target groups are the traffickers; they should be prevented from repeating the behaviour of trafficking children - hence the need for prosecution.

\section{Rehabilitation}

Delivery and facilitation of accommodation, rehabilitation and reintegration services must be rendered by the designated social worker. It is important to provide safe shelter for the children rescued from trafficking in order to prevent them from being re-trafficked. The provision of social counselling and rehabilitative assistance for the child victim is necessary to prepare the child for social reintegration and possible family reunification. The reintegration of the child into the community involves facilitating accessibility to schools, vocational training and other community activities or programmes (ECPAT, 2006:113).

\section{Reintegration}

During the reintegration process the social worker should be aware that it is long term in nature. It requires locating and tracing the child's family, coupled with thorough security and risk assessment to determine the best long-term care arrangements for such a child (ECPAT, 2006:113). Figure 1 illustrates and summarises the secondary and tertiary prevention of child trafficking with regard to the different stages of recovery as well as the reintegration process used when a trafficked child is being assisted (International Labour Organisation, 2006a:22). 


\section{FIGURE 1 \\ STAGES OF RECOVERY AND INTEGRATION \\ PROCESS}

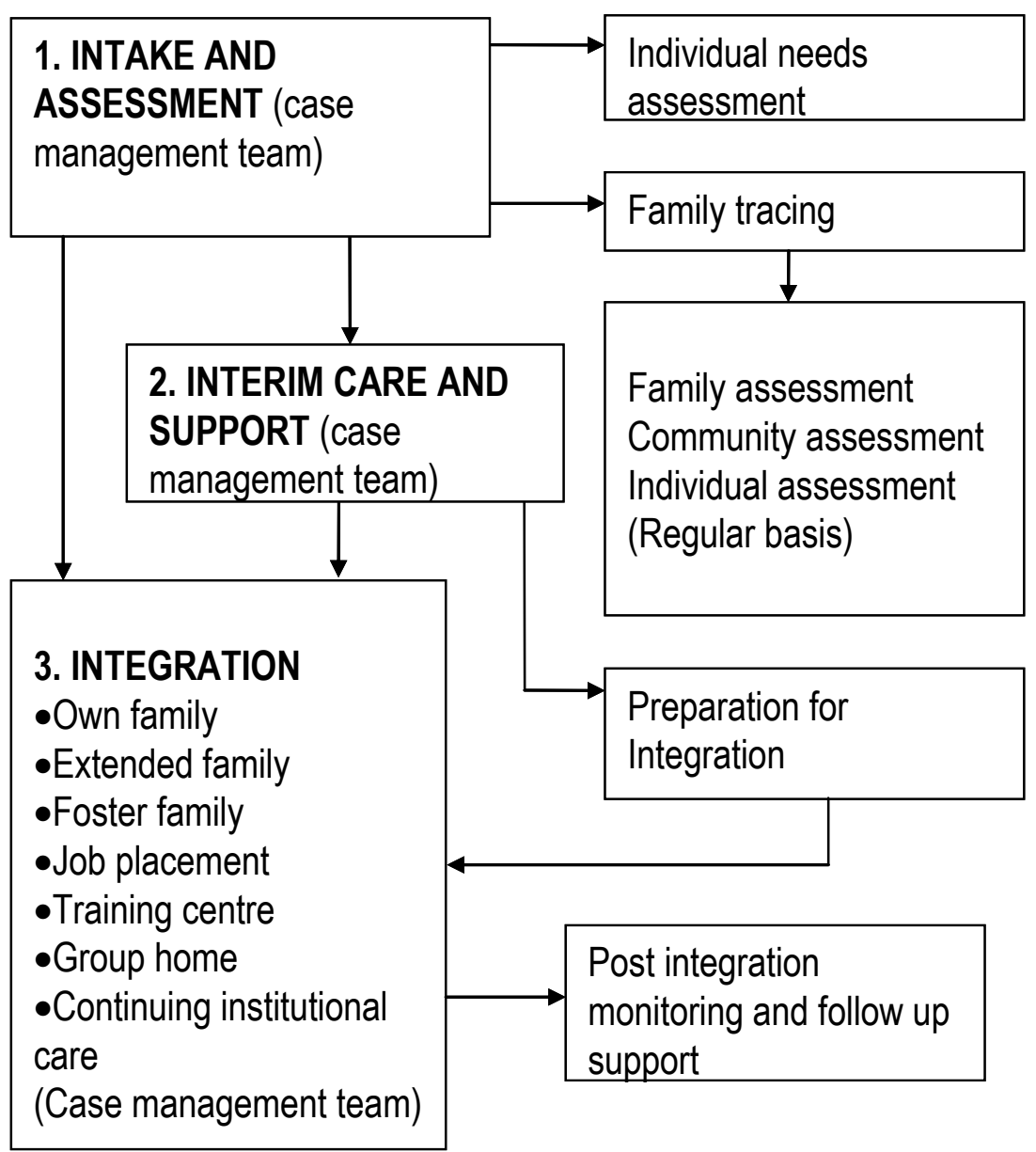

\section{RIGHTS AND SERVICES THROUGHOUT THE PROCESS}

*Safe and adequate
accommodation
*Legal support
*Physical health care
${ }^{*}$ Counselling and psychosocial
care education
*Vocational training and job
placement
*Life skills
*Recreational and culture
*Nutrition

Source: International Labour Organisation (2006a:22)

The researcher noted that throughout each of the three stages there are certain basic aspects of care that should be respected. Access to the community is important for the survivors of child trafficking. Therefore, during the integration process the children staying in shelters need intensive psychosocial support. Likewise, the right to education, medical care and good nutrition must be promoted in both interim care and during integration. The stages of recovery and integration process are discussed below.

\section{Intake and assessment}

The social worker conducts an individual needs assessment and attends to the child's most immediate needs, such as arranging counselling, medical attention and legal assistance. The needs assessment of the trafficked child should be updated on a regular basis until the child leaves the facility and integrates into society. Once family tracing is successful, then the family and community assessment begins (International Labour Organisation, 2006a:24).

Family assessment focuses on the economic status of the family to support the child, the risk of re-trafficking, the risk of reprisals by the traffickers, the risk of harm by the family through neglect or abuse, and changes in family structure since the child left (Thijs, 2006:25). Similarly, community assessment focuses on the community's attitude toward trafficked children and related issues such as prostitution, HIV/AIDS and political instability. 
The social worker should assess any risks of stigmatisation and social rejection, and action should be taken to prevent the child from being re-trafficked. Furthermore, the social worker should assess the types of resources that exist in the community that will support the child's integration process. Assessment should also focus on external factors that may place the child at risk of further abuse or neglect (International Labour Organisation, 2006a:25-26). From the beginning this is an individual participatory process where the child's expressed views and the best interests are the primary consideration.

\section{Interim care and support in recovery}

This is the stage of recovery and healing. The goal is the long-term and sustainable integration of the child into the family or community, and this process must start as soon as possible. The case management team involves social services, the legal guardian of the child, organisations and individuals experienced in caring for trafficked children (Thijs, 2006:27).

\section{Reintegration and continuing care}

The children may have gone back to their families of origin and joined other families such as an extended family system or foster care. In the case of adolescents, they may live independent of others while studying. However, according to the United Nations Office for Drugs and Crime (2006:127), the returned victims may still be traumatised and suffering from medical and psychological problems as a result of the experience. Therefore, bilateral efforts between the destination state and the state of origin are imperative to protect the child from danger and retaliation by the traffickers upon the victim's return.

Furthermore, a long-term placement, such as industrial schools or foster care, places the responsibility for the child's development in the hands of the community and family who are legally responsible for the child's care and welfare (Thijs, 2006:28).

\section{CHILD TRAFFICKING PROTECTION PROCESS}

The child trafficking protection process involves the physical treatment and rehabilitation which address the capacity to handle complicated child trafficking cases. This involves a wide range of perspectives used to analyse problems and arrive at solutions. Moreover, it is important to understand professional protocols and official processes for the handling of child trafficking cases that clearly identify the duties of the respective role players in preventing the problem.

Furthermore, it is imperative to ensure informed decision-making abilities among the role players involved. This will include more accurate investigations into the problem and the utilisation of more appropriate intervention approaches. The focus is on networking with other stakeholders in different areas of expertise to minimise system-inflicted trauma to children and their families as responses become more effectively coordinated and sensitive to children's needs. The child trafficking protection process is illustrated in diagram form in Figure 2. 
FIGURE 2

THE PROCESS OF CHILD TRAFFICKING PROTECTION

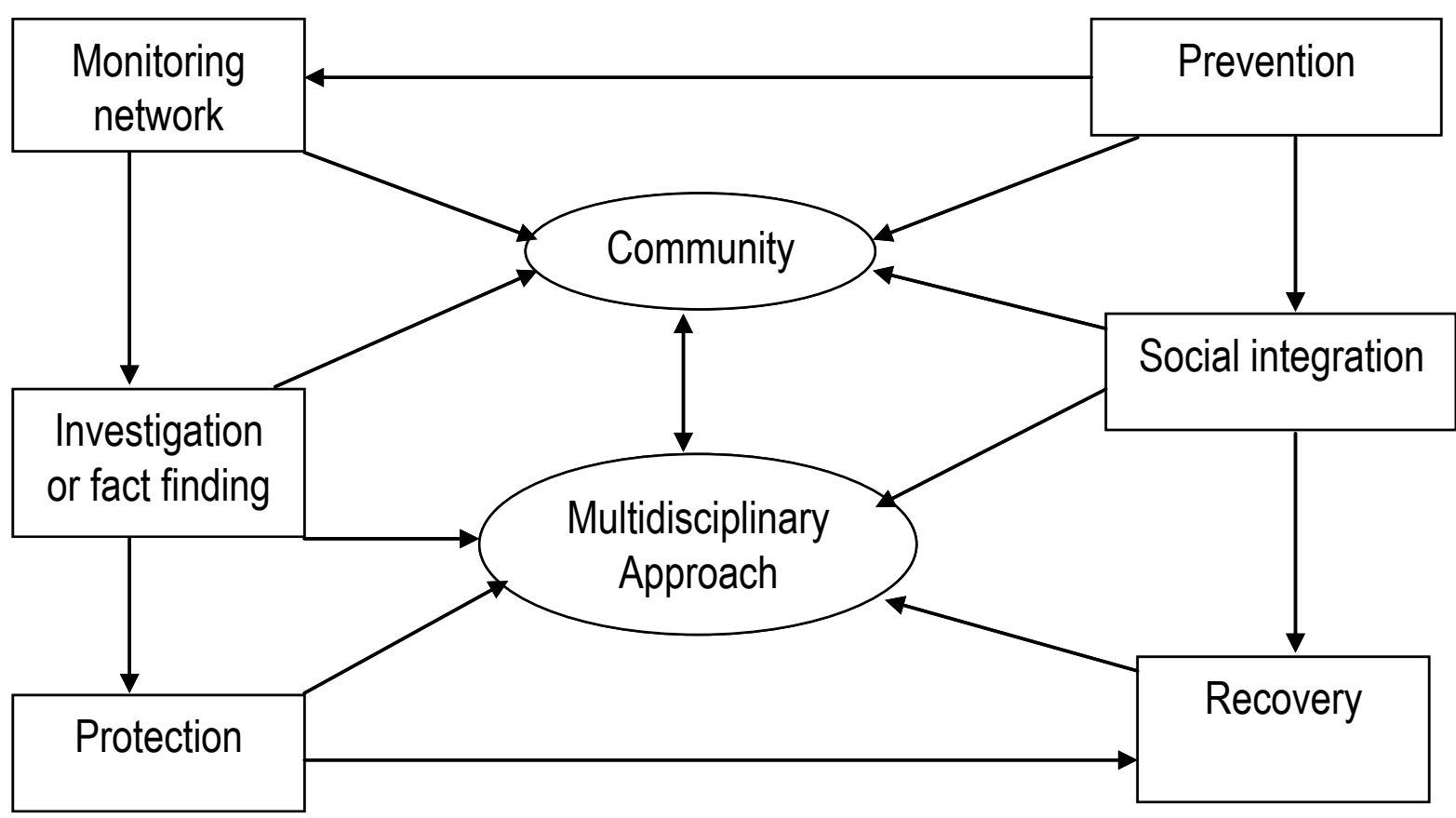

Adapted from Thaichildrights (2008)

\section{Monitoring network}

The community needs to initiate and build up some mechanisms for the close monitoring of child trafficking in the form of a child trafficking watch. Meanwhile, efforts must be made to create greater public awareness in schools, communities, hospitals and relevant practitioners to monitor children who are vulnerable to trafficking (Thaichildrights, 2008:5).

\section{Investigation or fact finding}

Upon receipt of suspected cases of child trafficking, the designated social worker must investigate and collect information that can be used to assess the victim. When the information on the child's physical, psychological and social status is being gathered, there will be a need to involve people from different fields such as paediatricians, psychiatrists, forensic doctors, police and lawyers (Thaichildrights, 2008:5).

\section{Protection}

The primary information gathered needs to be assessed to formulate a protection plan. The multidisciplinary team will hold a case conference to discuss and assess the problem, and to plan for protection. The United Nations Office for Drugs and Crime (2006:127) concurs with the above view and adds that the protection of trafficked children and the provision of assistance to enable smooth reintegration into their original environment is crucial.

\section{Recovery and treatment}

The child victim may need to receive psychological counselling. In addition, depending on the outcome of the primary assessment of the victim's social and physical condition, immediate medical treatment must be given.

\section{Social reintegration and prevention}

Through treatment and assessment by a multidisciplinary professional team the victims of child trafficking are prepared physically, mentally and socially for reintegration into the community. 
In addition, communities, schools and other organisations have to be prepared to ensure the children's safety. This also involves clearly stipulated roles and responsibilities for parents, guardians and caretakers of trafficked children. Furthermore, assistance should also prevent and protect the child from being trafficked (United Nations Office for Drugs and Crime, 2006:130).

\section{RESEARCH METHODOLOGY}

The motivation for this study was to understand the role of the social worker in the prevention of child trafficking in South Africa. Therefore a qualitative research approach was used to gain a holistic understanding of child trafficking (Fouché \& Delport, 2011:64-65). The social workers' perceptions regarding their role in the prevention of child trafficking were also explored. The most appropriate type of research used in this study was applied research to induce change (Fouché \& De Vos, 2011:94). The aim was to explore and identify the role of the social worker in the prevention of child trafficking in South Africa. An explorative collective case study research design was utilised through detailed and in-depth data-collection methods. To reach the goal of the study, the researcher used semi-structured, one-on-one interviews based on the interview schedule. The method allowed the respondents to share more freely in the direction that the interview took, which allowed the respondents to introduce issues the researcher had not thought about (Greeff, 2011:351). The respondents in this study were six social workers who work in different child protection organisations. The researcher sought general statements about relationships among categories of data and attached meaning to the collective case study research design on the perception of the social workers regarding their role in the prevention of child trafficking (Fouché \& Schurink, 2011:322 ).

\section{FINDINGS OF RESEARCH}

It is evident through the literature study that trafficked children are going through painful experiences, often characterised by economic hardships, torture, labour and sexual exploitation, as well as a lack of love. Furthermore, trafficked children are denied the right to education as they withdraw from school. They experience psychological distress and run the risk of being infected with HIV/AIDS from unprotected sex (The Frame Work, 2004:9). The above became clear when the respondents, six social workers from different organisations, narrated their views and experiences regarding their role in the prevention of child trafficking.

All six respondents expressed that they are not well equipped to deal effectively with trafficked cases and therefore they strongly suggested the need for special child trafficking legislation and guidelines to direct social workers in the intervention process. Evidently South Africa has no specific domestic legislation to prevent child trafficking. As a result of this, traffickers either get away scot-free or get a lesser punishment which does not match the criminal offence.

The empirical outcome has revealed that child trafficking is a challenging social problem and its dynamics requires specialised training of professional social workers. The researcher agrees with the respondents regarding the need for specialised training and raising awareness of vulnerable communities. This view is corroborated by the United Nations Educational, Scientific and Cultural Organisation (2007:59), which states that sustained concrete campaigns aimed at specific high-risk groups and readily identifiable social and professional groups will be most effective.

The findings will be discussed under each of the themes which formed the structure of the data gathered in the empirical study. The themes are outlined below. 


\section{Theoretical understanding of the concept child trafficking}

The views of the respondents with regard to their theoretical understanding of the concept child trafficking are summarised below.

From the empirical study it was evident that all six respondents had a basic understanding of child trafficking. All six respondents were able to define child trafficking. It was also apparent that the respondents knew the various factors that contribute to child trafficking as well as different forms of child trafficking. However, only one respondent seemed to have a more extensive understanding and she shared more information on the dynamics of both external and internal child trafficking.

With regard to the impact of child trafficking, it was apparent from the respondents' views that child trafficking victims experience severe psychosocial repercussions and debilitating effects. It was also evident that when dealing with child trafficking victims, social workers need to link up with other service providers to provide a more efficient and effective treatment to trafficked victims. This study confirms that the best interests of the child must be respected, especially when dealing with the life-threatening traumatic experiences of trafficked children.

There are a number of indicators that would enable social workers to identify the victims of child trafficking. However, it was apparent during the interviews that the majority of the respondents had little information to refer to that would support them in identifying trafficked children. All six respondents expressed that from the initial investigation in the form of interviews with the victim, one would be able to identify that the child is a victim of trafficking. During the interview the victims would give information which includes their recruitment, deception, mobilisation and later exploitation. Two respondents stated that a language problem could also be an indicator. It was evident that when a social worker comes into contact with an unaccompanied child who is not able to communicate in the local language, one can suspect child trafficking. It was found that most children used in the sex industry could be trafficked and forced to be sex workers. This can clearly be an indication, as no child who has developed normally would exchange sex for money. One respondent expressed the view that physical indicators enable the social workers to identify a trafficked child. The child might be beaten (for not complying with the trafficker's commands) and would have bruises, scars or red eyes. Another respondent indicated that another indicator could be that trafficked children may not know the physical address of the place and the names of the people with whom they were residing. This implies that trafficked children may have gone through different experiences of exploitation and can present different signs and symptomatic indicators. These indicators will enable the workers to identify the child as a victim of trafficking. The indicators range from psychological, physical, social and economic features.

\section{Views on the role of the social worker in the prevention of child trafficking}

All six respondents expressed the view that, at the primary prevention level of child trafficking, it is the social worker's role to raise awareness about child trafficking. Through their experience, the respondents stated that primary prevention should target vulnerable individuals, groups and communities. It was evident that the respondents were aware that the dissemination of information to the communities about the danger of child trafficking is paramount. However, the United Nations Educational, Scientific and Cultural Organisation (2007:38) reports that in spite of increased attention to the problem of trafficking by stakeholders in South Africa through the provision of information, the level of awareness in the population still remains very low. 
Three respondents stated that primary prevention methods of child trafficking involve capacity building of different role players. During the empirical study the respondents indicated that capacity building is the social worker's role. The social worker should capacitate other professionals and role players with child trafficking information in order to render quality services to trafficked children. This means that, in addition to social workers, medical personnel, police officers, immigration officials and teachers should be capacitated with information on child trafficking and its prevention.

Capacity building of community leaders and the consulate workers was considered to be important. Only one respondent mentioned that, in order to prevent child trafficking, it is the social worker's role to also capacitate community leaders through provision of child trafficking information, because they have influence over the community members. One respondent expressed the need for social workers to capacitate the consulate workers of different countries. This approach can help to prevent cross-border child trafficking.

It was found out that the social worker can play an advocacy role in the prevention of child trafficking. Two respondents indicated that it was the social worker's role to talk on behalf of the children by urging and lobbying the government to formulate and implement domestic antitrafficking legislation. Some of the respondents mentioned the importance of promoting the principle of ubuntu. The empirical study revealed that the respondents felt that it is their role to promote the principle of ubuntu among the community members in order to prevent child trafficking. Two respondents talked about social workers as initiators of economic projects with regard to empowering of individuals, groups and communities.

Throughout the empirical study the researcher noted that most of the respondents had very little information regarding the role of the social worker in the prevention of child trafficking. Most of the respondents focused on primary prevention through raising awareness. Two of the respondents indicated that the role of the social worker in secondary and tertiary prevention of child trafficking involves psychosocial support, provision of shelter, running of empowerment programmes and the need to reintegrate the trafficked child into society. It can be concluded that all the respondents indicated the need to take responsibility to prevent child trafficking, but that they lacked sufficient knowledge to do so.

\section{Perceptions regarding the services in place to protect victims of child trafficking}

All six respondents indicated that services to prevent children from being victimised by child trafficking are inadequate in South Africa. Additionally, a lack of knowledge among social workers regarding child trafficking in terms of victim identification as well as understanding the mind set of the victim and not knowing the type of services to be rendered perpetuates the situation. The lack of shelters in the country to accommodate victims of child trafficking contributes to the ineffective service rendering to trafficked children. This view is supported by Amnesty International (2009:3), which reports that survivors of child abuse in South Africa have few places to turn to for refuge. As the number of trafficked children becomes higher every year, so the number of sufficient, appropriate shelters to provide emergency and longterm shelter becomes increasingly inadequate.

There is a lack of specialised social workers in South Africa to attend to and meet the needs of trafficked children who have been rescued as well as to prevent them from falling into the trafficking trap again. It was evident that services are not effective because of lack of knowledge and lack of trained staff. The researcher's conclusion drawn from this is that the inadequacy of services in the fight against child trafficking is alarming. The situation results in 
the perpetuation of child trafficking and re-traumatising of trafficked children who have been rescued. Their best interests cannot be served at the current level of service rendering.

\section{Experiences regarding obstacles social workers face in the prevention of child trafficking}

All the respondents indicated that the lack of knowledge and training regarding child trafficking is one of the major obstacles which social workers face in the prevention of child trafficking. This study confirms that lack of knowledge about protection of trafficked victims and prevention of child trafficking results in poor service delivery. It was also found that, because of lack of knowledge and training, social workers often engage with trafficked children with prejudiced mind sets. This may lead to a situation where these children do not feel free to open up to the social workers.

One of the respondents clearly stated that the government's removal of the halfway passport issued to the International Organisation for Migration is another obstacle in the process to prevent child trafficking. As a result of this, the process to repatriate non-South African victims of trafficking takes longer than before. This may lead to unnecessary re-traumatisation. Language is viewed as one of the greatest barriers when social workers have to deal with trafficked children from foreign countries.

The lack of domestic human trafficking legislation to guide social workers in service delivery is a big obstacle. However, in the Children's Act, 2005 (Act No. 38 of 2005) prohibits trafficking in children:

\section{Trafficking in children prohibited}

\section{Section 283.}

(1) No person may traffic in children.

(2 The consent of a child who is a victim of trafficking to the intended exploitation is no defence to a charge of contravening subsection (1).

(3) If a court finds that the parent or care-giver of a child or any other person who has parental responsibilities and rights in respect of a child, has contravened subsection (1)in respect of that child, the court may-

(a) suspend all parental responsibilities and rights of that parent, care-giver or person pending an inquiry by a children's court; and (b) put that child in temporary safe care pending the placement of the child in alternative care.

\section{Victims of child trafficking found in Republic}

\section{Section 284.}

(1) Any child who is the victim of trafficking and who is found under circumstances which indicate that he or she is a child in need of care as contemplated in section 150 (a) must immediately be brought before the children's court for the district in which he or she was found in order to determine whether such child is a child in need of care and protection; and (b) may, pending such hearing, be placed in temporary safe care.

(2) The children's court may order that a child contemplated in subsection (1) be assisted in applying for asylum in terms of the Refugees Act, 1998 (Act No. 130).

However, there is a need to train social workers on the amended Children's Act of 2005. In addition, the Act is not specific with regard to prosecution of perpetrators. It was noted that lack of communication, trust and cooperation among service providers rendering services to 
trafficked children is viewed as an obstacle for participants in the prevention of child trafficking. The absence of a child trafficking forum to discuss difficult cases and generate new ideas to prevent child trafficking in South Africa and globally is a serious obstacle. The United Nations Educational, Scientific and Cultural Organisation (2007:60) confirms that communication channels to share and disseminate information on child trafficking must be seen as an important strategy. The researcher agrees that there are many unnecessary factors that hamper the prevention of child trafficking. Therefore, it is important for social workers to take note of these various obstacles in order to eliminate them in the process of their work.

\section{View on the availability of resources to support social workers in the prevention of child trafficking}

This study found that South Africa does not have sufficient resources to enable social workers to render services more efficiently to trafficked children. It was concluded that the country lacks resources such as manpower, infrastructure, knowledge and finances to address the prevention of child trafficking.

\section{Knowledge about the existing legislation related to child trafficking}

The majority of the respondents indicated that the absence of domestic legislation makes it difficult for the social workers to render effective services to trafficked children as there are no specific instruments to be used in the execution of their responsibility to prevent child trafficking. They further stated that South Africa uses the South African Constitution, the Child Care Act as well as the Sexual Offences Act as instruments to assist child trafficking victims, but they acknowledged that these instruments are not effective enough to support and protect all trafficked children.

Evidently the South African government, with the help of the South African Law Reform Commission, should prioritise and finalise the formulation and implementation of human trafficking legislation. According to the United Nations Educational, Scientific and Cultural Organisation (2007:38), South Africa does not have specific laws against human trafficking, but different legal tools are available to address some aspects of human trafficking activities. However, these instruments remain insufficient as they focus mainly on sexual offences. As a matter of urgency, respondent 6 suggested that it would have been wise for the government to pass the anti-trafficking legislation before 2010 FIFA Football World Cup. The assumption by respondent 6 was that many children were going to be trafficked into South Africa to serve in the prostitution and labour industry during the tournament period. However, the World Cup has passed and no anti-trafficking legislation has been passed yet. The delay in passing the trafficking bill into law poses a great challenge to the social workers as well as to other social service providers in the country with regard to service delivery to the child victims.

\section{Perceptions on training needs for social workers in the field of child trafficking}

All the respondents confirmed the importance of training to understand and prevent child trafficking. They specifically indicated that training will enable social workers to understand the psychology and dynamics of child trafficking. It will further enable service providers to understand the causes and effects of child trafficking, and the motives of traffickers. The United Nations Educational, Scientific and Cultural Organisation (2007:59-60) confirms that the establishment of community education programmes for the prevention of child trafficking is a non-negotiable requirement. The development of a training kit for local NGOs, civil authorities and other community actors to raise awareness is crucial. 
The training of social workers to prevent child trafficking needs to focus specifically on the role of the social workers, the effective use of current legislation, the effect of child trafficking on the life of a child, as well as how to identify a trafficked child.

\section{CONCLUSIONS AND RECOMMENDATIONS}

Evidence from the research suggests numerous recommendations, which are discussed below.

- Research has shown that social workers need to be trained to understand the dynamics of child trafficking, the effects on the trafficked child, the factors that contribute to child trafficking as well as the roles of the social worker in the prevention strategies. Training on the above aspects will enable social workers to render a more effective service to trafficked children. The training can take place through workshops and short courses, and child trafficking information could be incorporated into the curriculum at universities. Well trained social workers can inform communities through community development about the dynamics of child trafficking. This can strengthen the abilities of the social workers in the prevention of child trafficking. It can be concluded that training to help social workers and other service providers to gain more knowledge on child trafficking is imperative. The government and private sectors should collaborate to empower the social workers, who in return would empower vulnerable individuals, groups and communities.

- The social workers' roles in the prevention of child trafficking include knowledge dissemination. The social workers should impart knowledge to vulnerable and trafficked children, sensitise the community members about child trafficking, educate children on their fundamental rights and responsibilities which are necessary for their survival and protection from potential child traffickers, impart knowledge to other professionals and role prayers who work with children; social workers should also advocate on behalf of the vulnerable children and groups in the community.

- The social workers should promote capacity building by motivating the community members to be entrepreneurs, as well as initiating more income-generating projects in the communities to empower vulnerable groups. The social worker assigned to the trafficked child should act as a guardian in order to support the trafficked child whenever he or she seeks assistance from other sources. Moreover, the social worker should critically investigate and assess the needs of the trafficked children and accompany the trafficked children to relevant resources such medical or legal facilities, as well as facilitate the reintegration process. The social workers need to link vulnerable and trafficked children with other relevant services and resources, which requites a holistic approach such as providing psychological, medical, legal, police and educational assistance, as well as arranging attendance at church services and visiting Home Affairs. In view of the above, the social worker should be aware of the services and resources needed by the victims of child trafficking and how to access them. Social workers working in the Department of Social Services in collaboration with NGOs should also expand skills development programmes which can assist with the effective rehabilitation of rescued trafficked children as well as prevent them from going back to the trafficker. More awareness meetings or workshops with other professionals such as the police, immigration and medical personnel are necessary. In the same vein, social workers should engage with and empower school teachers and other professional role players in order to create a greater awareness among the community regarding the danger of child trafficking. 
- More adequate and secure accommodation needs to be provided by the government and NGOs for rescued trafficked children. Presently most child trafficking victims are kept in shelters for victims of domestic violence and abused children. However, child trafficking victims have different needs which require specialised and secure accommodation.

- Social workers should urgently lobby the government to revise the current policies to curb the growing problem of child trafficking. Child trafficking perpetrators escape punishment because of the absence of anti-child trafficking laws. Currently, the laws used to criminalise traffickers are lenient in relation to the scope of the crimes committed. The Child Care Act (No 74 of 1983 as amended in 2005) should be reviewed and adjusted to bring it in line with specific needs of the trafficked children. In addition, social workers should lobby for the bill on child trafficking drafted by the South African Reform Law Commission; it should be a priority for Parliament to pass this into law to prevent the escalation of child trafficking in South Africa.

- Research confirms that social workers need to collaborate with international and local stakeholders when working with trafficked children. Currently, specialised services in dealing with child trafficking are provided by international organisations such as the International Organisation for Migration. For long-term sustainability, local service providers should be empowered to take over such services. The Department of Social Services should deploy trained social workers who are equipped with child trafficking prevention strategies in other departments such as the police, immigration and civil aviation facilities (airports) to identify and deal with potential victims of child trafficking.

- The social workers should be more proactive and do more research on the topic of child trafficking. This will support them in playing a more prominent role in the prevention of child trafficking. While social workers are currently vaguely aware of the seriousness of child trafficking, very little research has been carried out to render an effective service on the primary, secondary and tertiary prevention levels. More South African-based research needs to be done to guide the social workers in their task of preventing child trafficking. The Department of Social Development could provide some resources for social workers to do the above-mentioned research. Scientific articles based on research need to be published as a way to sensitise professionals to the traumatic effects of child trafficking.

\section{REFERENCES}

AMNESTY INTERNATIONAL. 2009. Nowhere to shelter. [Online] Available: Www.amnesty.org. [Accessed: 05/04/2009].

ANTISLAVERY. 2003. Combating human trafficking for labour and sexual exploitation, Germany.

CINCOTTA, H., DISPASQUALE, D., HOLDEN, J., JOHNSON, C., McINTOSH, P., PAPLINGER, S. \& SINCLAIR, S. 2005. Working for women: world wide. Beijing Declaration and Platform for Action: Bureau of International Information Affairs.

CLAWSON, H.J., SALOMON, A. \& GRACE, L.G. 2008. Treating the hidden wounds: trauma treatment and mental health recovery for victims of human trafficking. Washington: USA Department of Health and Human Services.

DOTTRIDGE, M. 2004. Kids as commodities, International Federation. Switzerland and Germany: Terres des Hommes Foundation. 
ECPAT (End Child Prostitution, Child Pornography and Trafficking of Children for Sexual Purposes). 2006. Combating the trafficking in children for sexual purposes. Amsterdam: ECPAT International and Netherlands.

FOUCHÉ, C.B. \& DELPORT, C.S.L. 2011. Introduction to the research process. In: DE VOS, A.S., STRYDOM, H., FOUCHÉ, C.B. \& DELPORT, C.S.L. Research at grass roots for the social sciences and human service professions $\left(4^{\text {th }}\right.$ ed). Pretoria: Van Schaik Publishers.

FOUCHÉ, C.B. \& SCHURINK, W. 2011. Qualitative research designs. In: DE VOS, A.S., STRYDOM, H., FOUCHÉ, C.B. \& DELPORT, C.S.L. Research at grass roots for the social sciences and human service professions $\left(4^{\text {th }} \mathrm{ed}\right)$. Pretoria: Van Schaik Publishers.

FOUCHÉ, C.B. \& DE VOS, A.S. 2011. Formal formulations. In: DE VOS, A.S., STRYDOM, H., FOUCHÉ, C.B. \& DELPORT, C.S.L. Research at grass roots for the social sciences and human service professions $\left(4^{\text {th }} \mathrm{ed}\right)$. Pretoria: Van Schaik Publishers.

GLOBAL REPORT ON FORCED LABOUR. 2006. The end of child labour: within reach. Switzerland, Geneva.

GREEFF, M. 2011. Information collection: interviewing. In: DE VOS, A.S., STRYDOM, H., FOUCHÉ, C.B. \& DELPORT, C.S.L. Research at grass roots for the social sciences and human service professions $\left(4^{\text {th }}\right.$ ed). Pretoria: Van Schaik Publishers.

HOTALING, N., BURRIS, A.B., JOHNSON, B.J., BIRD, Y.M. \& MELBYE, K.A. 2003. Prostitution, trafficking and traumatic stress. New York: Haworth Maltreatment and Trauma Stress.

INTERNATIONAL ORGANISATION FOR MIGRATION. 2003. Eye on human trafficking. Bulletin of News, Information and Analysis on Trafficking in Persons in Southern Africa. Pretoria: IOM.

INTERNATIONAL LABOUR ORGANISATION. 2006a. Combating child trafficking: rehabilitation of the victims of child trafficking: a multidisciplinary approach. Bangkok: International Labour Office.

INTERNATIONAL LABOUR ORGANISATION. 2006b. Combating child trafficking: good practices in Asia prevention and rehabilitation, Bangkok: International Labour Office.

KELLY, R.J., MAGHAN, J. \& SERIO, J.D. 2005. Contemporary world issues: illicit trafficking, USA: ABC-CLIO Inc.

MARTENS, J., PIECZKOWSKI, M. \& VUUREN-SMITH, B. 2003. Seduction, sale and slavery: trafficking in women and children for sexual exploitation in Southern Africa ( $3^{\text {rd }}$ ed). Pretoria: International Organization for Migration.

MERTINEZ, M.L. 2007. Human trafficking: promising practices in the law enforcement, prosecutorial and victim assistance response. USA: Immigration and Customs Enforcement.

McDONNELL, M. 2006. Child trafficking a global, regional and national perspective. Botswana: Unpublished.

REDLINGER, J. 2004. Child trafficking and sexual exploitation. United States of America: University of Iowa.

RSA. MINISTRY OF JUSTICE AND CONSTITUTIONAL DEVELOPMENT. 2006. South African Children's Act, 2005. Government Gazette, Vol. 492 No 28944 (19 June). Cape 
Town. [On line] Available: http://www.info.gov.za/gazette.acts/2005/a38-05.pdf [Accessed: 20/05/2008].

SANGONet, 2004. No end to violence against children. Cape Town: Molo Songololo, Ford Foundation. [Online] Available: http://www.wcacf.org.za/about/molo.php [Accessed: 14/09/2008].

THAICHILDRIGHTS. 2008. Center for the protection of children's rights foundation. [Online] Available: www.thaichildrights.org (Accessed: 02/08/2008).

THE FRAME WORK. 2004. The frame work, for the protection, care and support of orphans and vulnerable children living in a world with HIV and AIDS. USA.

THIJS, G. 2006. Child friendly standards and guidelines for recovery and integration of trafficked children. Bangkok: International Labour Organization.

UGARTEL, M.A., ZARATE, L. \& FARLEY, M. 2003. Prostitution and trafficking of women and children from Mexico to the United States. Binghamaton, New York: The Howthorne Maltreatment Press.

UNITED NATIONS CHILDREN'S FUND. 2005. The State of The World's Children 2006 Excluded and Invisible. New York, United States of America: UNICEF House, United Nations Plaza.

UNITED NATIONS OFFICE FOR DRUGS AND CRIME. 2006. Toolkit to Combat Trafficking in Persons. New York. United Nations.

UNITED NATIONS PALERMO PROTOCOL ON TRAFFICKING IN PERSONS. 2000. Protocol to Prevent, Suppress and Punish Trafficking in Persons, Especially Women and Children, Supplementing the United Nations Convention Against Transnational Organized Crime. Italy: United Nations.

UNITED NATIONS EDUCATIONAL, SCIENTIFIC AND CULTURAL ORGANISATION. 2007. Human trafficking in South Africa, root causes and recommendations. Paris.

Mrs Juliet Patience Sambo, MSW (University of Pretoria, Department of Social Work); Prof Gloudien Spies, University of Pretoria, Department of Social Work, Pretoria, South Africa. 